Bibliotecas. Vol 40, № 1, enero - junio, 2022. EISSN: 1659-3286

URL: http://www.revistas.una.ac.cr/index.php/bibliotecas/index

DOI: http://dx.doi.org/10.15359/rb.40-1.3

Licencia: Creative Commons (BY-NC-SA) 4.0 Internacional

\title{
Los periódicos de la independencia. Los acervos hemerográficos digitalizados y su importancia para la investigación académica
} Independence era Newspapers. Digitized Collections and Their Importance for Academic

Research

\author{
Dra. Marybel Soto-Ramírez \\ Universidad Nacional, Costa Rica \\ ORCID: https://orcid.org/0000-0002-8804-7211
}

Recibido: 17 de mayo de 2021

Aceptado: 08 de setiembre de 2021

Publicado: 25 de enero de 2022

\section{Resumen:}

Este ensayo reflexiona sobre el valor de la prensa periódica como objeto de investigación para proponer que los procesos de digitalización de los acervos hemerográficos de la Biblioteca Nacional Miguel Obregón Loría son un invaluable apoyo para la labor académica. Plantea, asimismo, que la estrategia de preservación, indización y circulación es un porte a la democratización del acceso al conocimiento y a la información. Se concluye que la recuperación de periódicos publicados, poco después de la independencia, utilizados para la construcción de un micrositio dedicado al bicentenario es una valiosa veta para la investigación sobre pensamiento e ideas.

Palabras clave: prensa periódica, Biblioteca Miguel Obregón Loría, pensamiento latinoamericano, periódicos costarricenses, acervos digitales.

\section{Abstract}

This essay examines on the worth of periodicals as object of research and proposes that digitization processes of newspaper collections by the Miguel Obregón Loría National Library is an invaluable contribution for scholarly research. It also proposed that the strategy of preservation, indexing and circulation is a further contribution to the democratization access to knowledge and information. It is concluded that the recuperation of those newspapers that came to light shortly, after the independence of Costa Rica, and that were included in a microsite dedicated to the bicentennial's heritage, is an invaluable source for research on thought and ideas.

Keywords: periodical press, Miguel Obregón Loría National Library, Latin American thought, Costa Rican newspapers, digital collections. 


\section{Introducción}

A finales del siglo XX, la investigación académica atestigua un incremento en el estudio de la prensa periódica. Cobran vital importancia el estudio de las revistas culturales y de los periódicos, como espacios para analizar, un gran número de características, desde los aspectos físicos de los impresos, a los contextos de producción y circulación, así como en el campo de los estudios eidéticos, la recepción de ideas, los usos de lenguajes políticos, entre otros. Como vemos, es un campo de estudio provocador y amplio.

Se concuerda en que la prensa periódica, que incluye las revistas y los periódicos propiamente, es un elemento que identifica la cultura letrada en un momento y lugar dados. En periódicos y revistas se puede seguir el paso de las ideas, las apuestas de orden político y aspectos generales de construcción de un campo cultural; de construcciones identitarias y de género, de luchas de grupos diversos y, en el caso de los impresos decimonónicos, de la "invención de la nación".

Es posible afirmar que los periódicos, las revistas, los folletines y los volantes sirven como soportes materiales para la investigación del pensamiento y las ideas; son, por lo tanto, fuentes valiosas en la disciplina histórica, para estudios literarios y en general, estudios culturales. La importancia que juega la investigación de las publicaciones como medio de difusión cultural, científica, literaria y política en América Latina está sólidamente documentada (Pita y Grillo, 2013; Ovares, 2011; Crespo, 2010; Beigel, 2003; Oliva y Quesada, 2008; Sarlo, 1995, 2011).

En los impresos se puede rastrear el pensamiento de un autor, su presencia en el ámbito cultural o político, su influencia en la participación o establecimiento de redes textuales e intelectuales, la política editorial que anima la publicación, los circuitos de producción, los círculos de lectores y la construcción de la materialidad de formas de lectura, establecidas alrededor del impreso y desde este. 
En el caso costarricense, el investigador Iván Molina (1995) señala a Luis Dobles Segreda y a Jorge Lines como pioneros en la labor de identificar y clasificar los impresos publicados durante el siglo XIX. El investigador, sitúa en dicha labor "el punto de partida" para las investigaciones "sobre bibliotecas públicas y privadas, el tráfico y producción de impresos y el despliegue de la prensa (p. 13). La investigación del profesor Molina señala que, durante la época de la colonia, la circulación y consumo de libros fue escasa, circunscrita mayormente a la producción de libros píos en un ambiente conservador muy propio. Esta historiadora apunta asimismo lo siguiente: "...además de los interdictos oficiales y de los periódicos --en especial de Guatemala [...] que circularon ocasionalmente entre Cartago y San José, permitieron a los vecinos principales enterarse de lo que ocurría en el exterior..." (1995, p. 33).

En nuestro país el origen de la prensa se remonta a 1830, con la llegada de la primera imprenta, traída por don Miguel Carranza y denominada con el nombre de "La Paz". A partir de entonces, según explica el investigador Iván Molina, crece y se diversifica la circulación y el consumo de libros y periódicos: "El alza fue estimulada por el crecimiento demográfico, la urbanización de los cascos de los poblados principales, la organización de la educación pública y privada y el desarrollo institucional del Estado" (Palmer y Molina, 2004, p. 24).Para la historiadora Patricia Vega, sin embargo, dichos orígenes deben considerarse desde 1821, con la independencia de España, pues "no pueden obviarse los antecedentes necesarios para comprender el proceso evolutivo de las imprentas y de las publicaciones periódicas en el país" (1995, p. 11).Si contrastamos la llegada de la imprenta al país fue tardía, nueve años después de la independencia, en comparación con Guatemala, donde se contó con imprenta desde 1660, Panamá, desde 1821 o El Salvador, 1824; este retraso, tal como lo señala Iván Molina, es evidente y motivo de curiosidad investigativa.

No obstante, lo anteriormente expuesto, es interesante indicar que desde 1824 el jefe de Estado, Juan Mora, había dado el ejecútese a un decreto ${ }^{1}$ del Congreso que invitaba a los ciudadanos a establecer periódicos manuscritos, pues hacía descansar en ellos una forma de ilustración del pueblo, beneficiosa para apuntalar la libertad del Gobierno. Los periódicos manuscritos se mencionan, según la estudiosa Patricia Vega, desde 1824, en la Tertulia 
Patriótica, influyente grupo de participación de los ciudadanos ilustres, asociados con el poder y el comercio y el cual, según Vega, fue "el órgano político más importante de la época". La Tertulia Patriótica, a donde pertenecía Juan Mora Fernández, solicitó la adquisición de una imprenta, con el fin de lograr difundir las ideas "para zimentar (sic) la opinión que hace nuestro sistema político" (Vega, 1995, p. 30).

Quiere decir, entonces, que el papel brindado al periódico fue importante, como medio de difusión de ideas y como medio de ilustrar y educar. Es a ello a lo que la investigación académica apunta cuando señala que, en América Latina, la prensa cumplió una labor de orden social y educativo.

De acuerdo con don Adolfo Blen (1983), el Noticioso Universal de Costa Rica publicado por la Imprenta La Merced y El Correo de Costa Rica, por la Imprenta La Paz, salidos a la luz ambos en 1833 con tan solo un día de diferencia, son los impresos que dan origen a la prensa periódica en Costa Rica.

En la obra de Patricia Vega, De la Imprenta al periódico, los inicios de la comunicación impresa en Costa Rica 1821-1850 (1995), se señala que los periódicos se convierten en un espacio más metódico que los así denominados "papeles públicos" para la discusión de las ideas, y que luego de la aparición del Noticioso Universal, en 1833, ocurre una verdadera proliferación de periódicos.

Como vemos, el estudio de la prensa es apasionante. Es un soporte cultural desde donde indagar ideas y discursos e historiar el pensamiento que en ella se generó. La investigación académica la ha redescubierto como fuente y ha recurrido a ella ya no como algo menor a las labores de archivo, sino como un espacio de valor heurístico donde analizar la opinión pública, las expresiones políticas e ideológicas y, de manera muy valiosa, como un espacio para investigar las ideas; los periódicos dan cuenta de la realidad inmediata y sus interrelaciones en una sociedad. 
La investigación académica permite posicionarse en el periódico como artefacto complejo en su diversidad de funciones comunicativas, para comprenderlo como soporte material desde donde fluyen discursos en los que es posible rastrear matrices de pensamiento y prácticas discursivas que lo sustentan.

Como soporte cultural también es posible descubrir en el periódico un espacio de sociabilidad. La prensa periódica ha creado, históricamente en América Latina, espacios de instrucción, interlocución e interpelación, "constituyendo instancias decisivas en la formación de esferas públicas..." (Sábato, 2008, p. 387) por lo que es posible también analizar el periódico como producto de una práctica cultural de la cual es generador: el de opinión pública.

Concordamos en que la definición general de la prensa periódica escrita apunta a aquella publicación definida por su periodicidad en revistas, diarios, semanarios, anuarios; sin embargo, su característica fundante es su proyección hacia lo público, pues están pensados para que circulen y sean leídos por audiencias amplias para propagar, divulgar e informar noticias e ideas de la realidad política donde se inscribe: la publicación periódica da cuenta de novedades para informarlas (Sarlo, 1995).

Según Kircher, en su artículo La prensa escrita: actor social, político, espacio de producción cultural y fuente de información histórica (2005), la prensa cumple una función de testigo de todas las épocas, como actor social y político, pues:

...en tanto vidriera pública se convierte en un lugar inestimable para pensar la política y la sociedad, pero también permite visualizar la peculiaridad del objeto, inscripto permanentemente en un campo de relaciones que involucra actores, poderes, fuerzas políticas, y en la producción y puesta en circulación de temas y argumentos destinados a intervenir en el debate público y cultural. Desde esta perspectiva deviene en una fuente primordial para el estudio del proceso de configuración de las ideas políticas a partir de las formas discursivas del pensamiento. (p. 116) 
De acuerdo con Suriano (2008), la prensa y el periódico, como fuente histórica, brinda la flexibilidad temática y de acercamientos, lo cual favorece analizar períodos o hechos específicos, de ahí su carácter dinámico. "Como formadora de opinión y constitutiva del campo político, la prensa puede cuestionar o consagrar élites políticas y culturales, poner en tensión o legitimar prácticas políticas y construir su lugar en la esfera pública" (Kircher, 2005, p. 117).

El discurso de la prensa es portador de pensamiento, ya sea desde los editoriales que fijan en la programática de los impresos sus intervenciones o por las notas periodísticas que, en forma mucho menos estructurada quizá, pero más cercana e inmediata a la cotidianidad, revelan las preocupaciones y los esfuerzos de lucha y transformación de un colectivo a partir de los hechos que cubren.

El texto periodístico constituye un género discursivo. En él discurre la palabra escrita, el lenguaje en función, que construye significados, recrea la realidad, genera opinión, ejercita la agitación política y reproduce o reta la ideología dominante.

Latham y Scholes (2006) estudian un proyecto extraordinario denominado The Spectator Project e indican que la publicación periódica es un objeto históricamente coherente en términos culturales, donde lo explícito, pero también lo no dicho, los silencios, apuntan a una programática. Asimismo, destacan que, en el análisis de revistas y periódicos en la actualidad, en vez de separar números para analizar cuestiones específicas, el conjunto como un todo, ha permitido visualizar un objeto autónomo de estudio, un texto completo en sí mismo, en su complejidad y completitud, y no como un simple receptáculo de información.

Erlicher y Ribler-Pipka (2014) denominan los impresos de una manera metafóricamente hermosa como "almacenes de un tiempo en fuga" ( $\mathrm{s} / \mathrm{p}$ ). Tanto ellos como Alexandra Pita (2009) señalan que los periódicos no son simples contenedores o depósitos de textos, si no que tienen valor en sí mismos, como objetos. De ahí también la importancia cuando estos mudan de soporte para convertirse en objetos digitales. 
De acuerdo con Latham y Scholes "...como parte integral o paralelamente al gran campo de la cultura impresa, una nueva área académica surge entre las Humanidades y las ciencias sociales más humanísticas: los estudios de prensa periódica”.(2006, p. 517), con lo que nos plantean una nueva área de investigación: los estudios sobre publicaciones periódicas, como campo de estudio, posibilitado en gran medida en la actualidad porque la era digital ha permitido poner a disposición de la academia importantes acervos documentales, con ediciones y corpus completos de revistas y periódicos.

\section{La digitalización de acervos bibliográficos: una puesta en valor}

Hasta aquí es claro el valor de los periódicos para la investigación en sus variadas posibilidades. Es necesario ahora señalar que, para poder realizar investigación sobre periódicos, o en los periódicos, la accesibilidad a la fuente es un aspecto decisivo. Efectivamente, lo primordial para la persona investigadora es la ubicación de estos materiales hemerográficos para la construcción de corpus, como herramienta metodológica para la realización de los estudios. Ambas labores, ubicación de las fuentes y construcción de corpus, formaban parte de la extenuante labor de archivo. Lograr acceso a colecciones restringidas, por la protección de los materiales, cuando se contaba la suerte de ubicarlos en una biblioteca pública, el proceso de reproducción o de fichaje de información, hacían de esta una tarea muy ardua.

No pocas veces, la búsqueda se convertía en algo titánico, una búsqueda casi mística, en la reconstrucción de ejemplares semidestruidos por el tiempo o a la caza de ejemplares sueltos, perdidos en casas de anticuarios, libreros de fondistas o librerías de viejo, esos esenciales espacios de la tradición literaria que agrupa los materiales descatalogados y raros $^{2}$.

Los esfuerzos de preservación ${ }^{3}$ de acervos son necesarios e importantes en sí mismos. A lo largo del tiempo, se han realizado desde microfilms hasta reproducciones facsimilares de ediciones archivándolas en dispositivos, que usualmente, con el paso del tiempo, degradaban la información. Por eso, no es sino hasta el advenimiento de la era digital, donde ha sido posible trasladar archivos completos de soporte impreso a soporte digital convirtiéndose en un sueño cumplido, largamente acariciado, para profesionales de la información y para investigadores. 
Es precisamente la puesta en marcha de estos procesos de intervención, recuperación y puesta en acceso al público lo que ha permitido que la investigación académica logre una importante escalada en años recientes, a tan alto nivel para dar resultado a lo que los estudiosos Latham y Scholes apuntan como un nuevo campo de estudios emergente en las Humanidades: estudios de la prensa periódica que ofrece un campo novedoso para la investigación de los periódicos como objetos, como textos completos, y con visión interdisciplinaria, donde historia, comunicación, literatura, las mismas áreas de edición y, por supuesto, la informática brindan un campo fascinante.

La ingente tarea de digitalización de periódicos y revistas que ha llevado a cabo la Biblioteca Nacional no puede calificarse sino de encomiable. $Y$ en ello debe reconocerse el esfuerzo realizado por las autoridades y funcionarios de la Biblioteca, porque están generando para las comunidades futuras, un proceso de preservación invaluable; es lo que el gran conservacionista del National Trust of Historical Conservation, Prof. William J. Murtag declaró: «La preservación pone el pasado a conversar con el presente por un mutuo interés en el futuro» (1988, p. 168); pero además, al poner en línea estos materiales disponibles para la consulta, multiplican las posibilidades de la investigación y de las metodologías empleadas para ello.

La interesante apuesta de Latham y Scholes señala, de los nuevos enfoques, que la digitalización y el acceso a los materiales permiten a la investigación remover el obstáculo de acceso a las fuentes, proveyéndose, a su vez, la protección, es decir, la preservación, del material. Es decir, este ejercicio que viene realizando la Biblioteca Nacional de Costa Rica, va más allá de una operación, compleja ciertamente, de traslado entre soportes; sino que avanza a la democratización en el acceso a la información.

La creación del acervo digital nos permite a todos los costarricenses, tener acceso a información antes restringida a un selecto grupo de investigadores y poder disfrutar, como es el caso, de ese primer periódico del que nos hablaban los investigadores Molina y Vega, que luego de la independencia se publicó por la imprenta La Merced, El Noticioso Universal. Y 
luego de él, el Correo, La Tertulia, Ensayos de Libertad, La Aurora, La Gaceta, La Paz y el Progreso... todos ellos están en este nuevo soporte ${ }^{4}$.

La elaboración de subsitios y exhibiciones permiten disfrutar a toda la población de este tipo de materiales raros; por ejemplo, el dedicado a la Independencia de Costa Rica, donde se ha recopilado aquellos periódicos que, a lo largo del período, conmemoran la efeméride. Tal como referían los investigadores Erlicher y Ribler Pipka, los periódicos no son ya almacenes de un tiempo en fuga que atesoran, ahora en bits, la memoria de la cultura impresa y letrada en un momento dado. Es toda una nueva forma y estilo de trabajo en las humanidades digitales ${ }^{5}$.

Los retos actuales, en la multiplicidad de tareas sobre el valor de la digitalización de acervos hemerográficos, se deberá orientar a lograr completar y en acopiar ediciones nuevas, en proceso de restauración o números faltantes de las colecciones, donde el fin de preservar, restaurar, indizar y poner a disposición de las comunidades académicas y de la sociedad como un todo, es el paso que deberá de seguirse en este esfuerzo. Esa es la labor de la biblioteca pública, como institución de cultura y de conservación de la memoria. El entorno digital trae consigo posibilidades extraordinarias para la investigación inter y transdiciplinaria en este tipo de acervos. A su vez, rompe el esquema de la biblioteca como lugar concreto para tornarse a la ubicuidad del hiperespacio textual gracias a la puesta en línea de dichas colecciones.

A modo de un cierre de estas reflexiones, en este sentido, debe considerarse que en el entorno virtual la estrategia del acceso abierto aspira a lograr un más amplio al disfrute de los bienes culturales resultantes de la investigación, democratizando, de esta forma, el acceso al conocimiento. Los procesos realizados desde el entorno digital con el acceso abierto y en el ámbito de las publicaciones periódicas contemporáneas, se favorece la puesta en discusión pública de los resultados del quehacer académico de forma casi inmediata y, para el caso de la prensa periódica histórica, la digitalización aporta a la preservación de lo que muchos de nosotros aún continuamos denominando como "impresos" pero que ya han mudado -y se espera que continúen haciéndolo- hacia esos nuevos soportes, sin perderse por ello, el valor de su materialidad. 
Ello representa sin duda una nueva sensibilidad desde la cual acercarse a los documentos en términos profesionales, pero también por parte de la población en general, la cual podrá descubrir ese "lieú" o lugar de memoria. Por ejemplo, resulta muy interesante corroborar cómo varias páginas de redes sociales han establecido comunidades de usuarios que disfrutan acercarse a periódicos y revistas antiguas, rescatando de ellas fotografías, textos, anuncios curiosos y sobre todo, de muy buen talante, formas de lenguaje y precios de productos de inicios de siglo. La notación de la fuente de donde se toman esos "repertorios" señalan, en buena medida, al portal de la Biblioteca Nacional y a la Sala de Libros Antiguos de la Biblioteca Joaquín García Monge ${ }^{6}$.

No es arriesgado señalar que el esfuerzo de la benemérita Biblioteca Miguel Obregón Loría es loable y representa un inmenso impacto a la labor académica en las humanidades y las ciencias sociales, en áreas específicas como las biografías intelectuales, la historia de las ideas y la historia intelectual, donde el acceso a la fuente es decisivo. Con ella, el valor de la construcción de corpus integrales deja de ser solo un insumo para constituirse en sí misma, en aporte a la investigación.

Cada vez más, para gozo de quienes nos asumimos en estas ramas del saber, se construyen y se ponen a disposición de la academia y de la sociedad en general, bibliotecas, sitios, portales y repositorios online, de acceso libre y a texto completo, con lo cual, también la distribución de contenidos ha venido a cambiar los modos de investigar así como las formas de producción y circulación de conocimiento, revelando la conformación de espacios informacionales para la labor académica, concretando un universo de estudio apasionante. Es necesario asimismo referir brevemente a que la construcción de objetos digitales con registros persistentes, como una buena práctica del entorno y la alfabetización digital.

Por ello, particularmente en momentos celebratorios como el presente, de cara al bicentenario de la independencia de Costa Rica, se hace necesario reconocer que gracias a estos y otros procesos de transformación digital cifrados en este ensayo en la Benemérita Biblioteca Nacional de Costa Rica, que la sociedad costarricense -y más allá de sus fronteras- logra 
disfrutar de un minisitio que guarda un pedacito de esa historia que ha sido forjada en 200 años de vida independiente y sobre cuyos fondos, se continuará investigando, gracias a estas herramientas tecnológicas y en particular, gracias al apoyo y visión profesional de quienes facilitan este nuevo salto de la cultura impresa al acervo digital, en sus diversos formatos.

\section{Referencias bibliográficas}

Beigel, F. (2003). Las revistas culturales como documentos de la historia latinoamericana. Utopía y Praxis Latinoamericana: revista internacional de filosofía iberoamericana y teoría social 20, 105-116.

Blen, A. (1983). Historia del periodismo. Costa Rica: Editorial Costa Rica.

Crespo, R. (2010). (Coord.). Revistas en América Latina: proyectos literarios, políticos y Culturales. México: UNAM.

Erlicher, H. y Ribler-Pipka, N. (2014). Almacenes de un tiempo en fuga. Tübingen, revistas culturales 2.0. Recuperado de https://www.revistas-culturales.de/es/buchseite/hannoehrlicher-nanette-ri\%C3\%9Fler-pipka-eds-almacenes-de-un-tiempo-en-fuga-revistas)

Kircher, M. (2005). La prensa escrita: actor social, político, espacio de producción cultural y fuente de información histórica. Revista de Historia, 5, Universidad de Comahue, pp. 115-122

Latham, S., Scholes, R. (2006). The Rise of Periodical Studies. PMLA,121(2) Cambridge University Press.

Molina, I. (1995). El que quiera divertirse. Libros y sociedad en Costa Rica (1750-1914). Costa Rica: EUNA.

Murtag, W.J. (1988). Keeping Time: The History and Theory of Preservation in America. New York: Sterling Pub.Co.

Ovares, F. (2011). Crónicas de lo efímero. Revistas literarias de Costa Rica. Costa Rica: EUNED.

Oliva, M. y Quesada, R. (2008).El pensamiento antiimperialista de Octavio Jiménez. Antología de estampas publicadas en Repertorio Americano. Costa Rica: EUNED.

Palmer, S., Molina, I. (2004). La voluntad radiante. Cultura impresa, magia y medicina en Costa Rica (1897-1932). Costa Rica: EUNED.

Pita, A. (2009). La Unión Latino Americana y el Boletín Renovación. Redes intelectuales y revistas culturales de la década de 1920. México: COLMEX.

Pita, A. y Grillo, M. (2013). Revistas culturales y redes intelectuales. Una aproximación metodológica. Temas de Nuestra América Revista de Estudios Latinoamericanos 29(54), 177-194. Recuperado de https://www.revistas.una.ac.cr/index.php/tdna/article/view/6338 
Sábato, H. (2008). Nuevos espacios de formación y actuación intelectual: prensa, asociaciones, esfera pública (1850-1900). En J. Myers (Ed.), Historia de los intelectuales en América Latina. Argentina: Katz Eds.

Sarlo, B. (1995). Intelectuales y revistas, razones de una práctica. Cahiers du CRICCAL, 9(2),9-16.

Sarlo, B. (2011). El imperio de los sentimientos. Narraciones de circulación periódica en la Argentina. Argentina: Siglo XXI.

Suriano, J. (2008). La prensa como fuente privilegiada para los estudios históricos. (Dossier). Papeles de trabajo. Revista Electrónica del Instituto de Altos Estudios de la USAM, 2(3), IDAES/UMSAM, pp. 180

Vega, P. (1995). De la imprenta al periódico. Los inicios de la comunicación impresa en Costa Rica. 1821-1850. Costa Rica: Editorial Porvenir.

\section{Notas de la autora}

Doctora. Marybel Soto-Ramírez. Académica del Instituto de Estudios Latinoamericanos (IDELA), Universidad Nacional, Costa Rica. Correo electrónico: msot@una.ac.cr. ORCID: https://orcid.org/0000-0002-8804-7211

${ }^{1}$ Decreto XXIII del 25 de noviembre de 1824; véase El periodismo en Costa Rica, de don Adolfo Blen, Editorial Costa Rica, 1983.

${ }^{2}$ Recuérdese la tradición de los buquinistas, vendedores ambulantes de libros raros, actividad reconocida en Francia desde 1578 y con permanencia aún en la actualidad en la capital francesa y en España.

3 Nótese la diferencia de alcance entre los términos conservación y preservación, para la mejor comprensión de lo que este último implica, según define el RAE. Véase: La preservación de los fondos documentales en los Archivos “...preservar es proteger, resguardar anticipadamente a alguien o algo, de algún daño o peligro. Por lo tanto, la preservación es la primera fase y abarca toda clase de actividades económicas y administrativas al servicio de la prevención con el deterioro de los documentos" En:https://www.comunidadbaratz.com/blog/la-preservacion-del-fondo-documental-en-losarchivos/

${ }^{4}$ Véasehttp://www.sinabi.go.cr/biblioteca\%20digital/periodicos/\#.YJtD0tUzbcs

${ }^{5}$ Véase Kathleen, F. (2012). The Humanities done Digital. Mathew K. Gold (Ed.) Debates in Digital Humanities, https://doi.org/10.5749/9781452963754

${ }^{6}$ Heredia y su heredianismo, Casas antiguas de Costa Rica y en algunos casos Desde el Fortín, son algunas de dichas comunidades en Facebook que publican este tipo de referencias. 